\title{
Strategies for the Reconstitution and Purification of Haloarchael Protein RadA
}

\author{
Bushra B. Patoli ${ }^{* 1,2}$ and Atif A. Patoli ${ }^{2}$ \\ ${ }^{* 1}$ Institute of Microbiology, University of Sindh, Jamshoro, Pakistan. \\ ${ }^{2}$ School of Biology, Queens Medical Centre, University of Nottingham, Nottingham, NG7 2UH, UK. \\ *Corresponding Author Email: bushrapatoli@gmail.com \\ Received 13 March 2019, Revised 16 September 2019, Accepted 20 October 2019
}

\begin{abstract}
DNA repair proteins in halophilic organisms are interesting to study in the context of understanding the dynamics of protein-DNA interaction and their adaptation to perform biochemical activities at high osmolarity. Successful expression and purification of halophilic proteins is often challenging particularly when they are over-expressed in non-halophilic heterologous host. In the present study, radA from Haloferax volcanii was cloned and overexpressed in E. coli. Although, radA was over-expressed as a soluble protein in E. coli but purification of RadA seemed challenging. Various strategies were therefore implemented to attain maximum possible purification of RadA. The purification of RadA using Immobilized Metal Affinity Chromatography (IMAC) followed by Size Exclusion Chromatography (SEC) was initially adopted. The SDS-PAGE and agarose gel analysis of the representative fractions from SEC indicated this to be an unsuccessful strategy due to high affinity of protein with the DNA from host. The refolding strategy employing denaturation of the RadA in urea along with benzonase treatment was attempted to chop down the contaminating host DNA. This was observed an effective method as the subsequent analysis of the representative fractions from SEC indicated RadA at about $90 \%$ purity that can possibly be suitable for further biochemical and structural analysis.
\end{abstract}

Keywords: RadA, Haloferax volcanii, Homologous recombination, refolding strategy.

\section{Introduction}

The living organisms are equipped with several DNA-repair mechanisms to restore the damages in genomic DNA. Homologous recombination (HR) is one of the faithful and efficient strategy used to repair potentially lethal DNA lesions like, stalled replication forks or breaks and gaps in single or double stranded DNA (ssDNA or dsDNA) molecule [1]. The damage in DNA is restored by recombination between two duplex DNA molecules at the homologous DNA sequences [2]. The key step in the homologous recombination is the strand exchange reaction in which two duplex DNA strands interact and bring about either exchange (crossover) or replacement (gene conversion) of DNA region [3]. This reaction is catalyzed by conserved recombinase enzyme belong to the RecA family of proteins. The recombinase proteins are designated as RecA in bacteria [4], Rad51 in eukaryotes [5], and RadA in archaea [6]. These proteins share significant sequence homology in their conserved motifs, responsible for interaction with DNA and other regulatory proteins. RadA protein in archaea functions as recombinase enzyme and holds a close similarity at the structural and sequence level to RecA in bacteria and Rad51 in eukaryotes [7].

Haloferax volcanii ( $H$. volcanii) is one of the archaeal species belonging to the phylum Euryarchaeota. The archaeon was isolated from the 
sediments of Dead Sea where the sodium chloride and magnesium chloride enrichment is up to $3 \mathrm{M}$ [8]. RadA has been characterized in different crenarchaeal and euryarchaeal species [9-11]. Although archaeal RadA shares close structural and functional similarity to the recombinase proteins in other domains of life, however the reaction kinetics are quite specific for each protein in the strand exchange process $[10,12,13]$, depending on the nature and origin of protein. The abundance of anionic residues like (Aspartate and Glutamate) make the topography of halophilic proteins distinct from the other proteins and hence influence the dynamics of protein-protein and protein-DNA interactions within the cells [14]. Characterization of DNA-binding proteins suggests that DNA-protein interactions are sensitive to the presence of salt [15]. For example, the interaction of mesophilic proteins with DNA is quite susceptible to high salt concentration, whereas the reverse is true for the halophilic proteins [16]. The addition of cations at the interface of poly-anionic DNA and negatively charged protein prevents the charge repulsion and favors the interaction between two macromolecules $[15,16]$.This suggests that protein-DNA interaction in halophilic organisms is mediated through mechanisms, which differ to that found in the mesophilic counterparts. Purification and characterization of DNA binding proteins from halophilic organisms is interesting to study and understand the dynamics of protein and DNA interaction at high osmolarity in this domain of life.

Given the facts that the investigation of proteins from extremophiles provides additional information about the different mechanisms of DNA information processing pathways, we set the ultimate objective of this study to over-express Hvo radA gene in Escherichia coli (E. coli) and purify RadA protein for the biochemical and structural characterization.

\section{Materials and Methods}

\section{Cloning and Over Expression of Hvo Rada}

Plasmid $p 29$ encoding Hvo radA (1032bp) was provided by Dr. Aller's lab at University of Nottingham, UK. For the over-expression purposes in a eubacterial expression vector, radA was amplified using a forward primer (radA 6HisF), encoding an NdeI restriction site and a 6xHis tag (GACCTCATATGCATCACCATCACCATCAC ATGGCAGAAGACGACCTC) and the reverse primer (radABamR) encoding a BamHI restriction site (GCAATGGATCCTTATTACTCGGGCTTG AGACCGGCGTCCTG). Amplification of $\mathrm{radA}$ was performed by A MULTI-GENE thermocycler (Labnet). The PCR reaction conditions used were; initial denaturation at $96^{\circ} \mathrm{C}$ for $5 \mathrm{~min}$, followed by 30 cycles of denaturation at $96^{\circ} \mathrm{C}$ for $2.5 \mathrm{~min}$, annealing at $60^{\circ} \mathrm{C}$ for $1 \mathrm{~min}$ and extension at $72^{\circ} \mathrm{C}$ for $1 \mathrm{~min}$. The final extension was performed at $72^{\circ} \mathrm{C}$ for 5 minutes. The amplified $\mathrm{radA}$ gene was initially cloned into the zero blunt PCR vector (Novagen) and latter sub-cloned for overexpression into pET11 using NdeI and BamHI restriction enzymes. The construct was named as pBPRAD1. Rosetta2 (DE3) E. coli expression strain was transformed with $p$ BPRAD1 for the over-expression of radA [14].

Fresh transformants encoding $\mathrm{radA}$ were grown in Luria-Bertani (LB) broth containing appropriate antibiotics at $37^{\circ} \mathrm{C}$. Cells were induced with $0.1 \mathrm{mM}$ IPTG at OD600 $=0.6-0.8$ with further incubation of $4-5$ hours at $25^{\circ} \mathrm{C}$. The cells were then harvested by centrifugation.

\section{Purification of RadA}

For purification of RadA, a cell pellet from $400 \mathrm{ml}$ of culture volume was re-suspended in buffer containing $50 \mathrm{mM}$ HEPES (pH 7.0), $10 \mathrm{mM}$ imidazole and $1 \mathrm{M} \mathrm{NaCl}$ with a protease inhibitor tablet (Roche). The cells were lysed by sonication on ice at amplitude of $10 \mu \mathrm{m}$.

Soluble protein was obtained by spinning the cell lysate at $15000 \mathrm{rpm}$ for $30 \mathrm{~min}$ at highspeed refrigerated centrifuge (Sorvall RC5B plus SS34 rotor). All the batch purifications were performed using $5 \mathrm{~mL}$ of Talon slurry (Clontech) in a Liquid Chromatography Column, (Size: 2.5 $\mathrm{cm} \times 10 \mathrm{~cm}$, bed: $49 \mathrm{~mL}$.-Sigma-Aldrich). For this the column was equilibrated with 20-column volume of buffer containing $50 \mathrm{mM}$ HEPES $(\mathrm{pH}$ 7.0), $30 \mathrm{mM}$ imidazole and $1 \mathrm{M} \mathrm{NaCl}$. The soluble fraction was loaded and incubated with rolling for $10 \mathrm{~min}$ at room temperature. Bound proteins were 
eluted with $13 \mathrm{~mL}$ of Talon buffer containing 50 mM HEPES ( $\mathrm{pH}$ 7.0), $300 \mathrm{mM}$ imidazole and $1 \mathrm{M}$ $\mathrm{NaCl}$ after rolling for 5 minutes at room temperature. The eluted protein was loaded on 26/60 Superdex 200 preparative SEC column (GE Healthcare). The column was pre-equilibrated in $50 \mathrm{mM}$ HEPES $(\mathrm{pH} 7.0)$ and $1.0 \mathrm{M} \mathrm{NaCl}$. The column was run at a flow rate of $2 \mathrm{~mL} / \mathrm{min}$ and 10 $\mathrm{ml}$ fractions were collected between 100 and 300 ml. elution volume.

\section{Polyethylenimine (PEI) Precipitation Assay}

Polyethylenimine (Sigma-Aldrich) was prepared as a $5 \%[\mathrm{w} / \mathrm{v}]$ stock solution in $50 \mathrm{mM}$ Tris- $\mathrm{HCl}(\mathrm{pH}$ 7.5) buffer and stored at room temperature in the dark. A drop-wise solution of $0.05 \%$ of PEI was mixed with soluble lysate containing RadA with continuous stirring on ice and incubated until it turned cloudy. The solution was centrifuged for $10 \mathrm{~min}$ at $4000 \mathrm{rpm}$ to obtain the clarified supernatant. The supernatant was purified by Talon metal affinity chromatography and Size Exclusion Chromatography (SEC). The pellets were given three subsequent washes with $300 \mathrm{mM}, 500 \mathrm{mM}$, and $1 \mathrm{M} \mathrm{NH}_{3} \mathrm{SO}_{4}$, and spun at $4600 \mathrm{rpm}$ for $10 \mathrm{~min}$ each time. The supernatant and re-suspended pellets were collected at each stage for protein and DNA analysis using SDSPAGE and agarose gel electrophoresis.

\section{On-column Refolding of RadA Using Nickel Based Affinity Column}

Cells containing recombinant RadA (Rosetta2 (DE3)) were lysed in buffer containing $50 \mathrm{mM}$ HEPES (pH7.0), $500 \mathrm{mM} \mathrm{NaCl}, 6 \mathrm{mM}$ $\mathrm{MgCl}_{2}, 40 \mathrm{mM}$ imidazole and protease inhibitor, as described previously. Soluble lysate was incubated with $2 \mu \mathrm{l} / \mathrm{mL}$ benzonase (Invitrogen) with constant rolling for $2 \mathrm{~h}$ at room temperature. Solid urea was added at final concentration of $6 \mathrm{M}$ with the incubation of $30 \mathrm{~min}$ to permit the unfolding of proteins. Additional benzonase $(2 \mu \mathrm{l} / \mathrm{mL})$ was added after half an hour with a further incubation of $30 \mathrm{~min}$ at room temperature. At each step, the samples were taken for analysis by SDS-PAGE. The lysate obtained was loaded on to a $5 \mathrm{~mL}$ Nickel-based HisTrap column (GE Healthcare). The affinity column was equilibrated with $10 \mathrm{CV}$ of binding buffer containing $6 \mathrm{M}$ urea. On-column refolding of $\operatorname{RadA}$ was achieved through a decreasing gradient of denaturant in the refolding buffer followed by elution in HEPES buffer containing $300 \mathrm{mM}$ imidazole.

\section{SDS-PAGE-Analysis}

Protein samples were analyzed using $12 \%$ SDS-PAGE gels (Severn Biotech) set in Novex 1.0 mm cassettes (Invitrogen). $15 \mu \mathrm{L}$ of protein sample was mixed with $5 \mu \mathrm{L}$ of gel loading buffer and heated up to $95^{\circ} \mathrm{C}$. The samples were loaded on SDS-PAGE gel. The gels were run at $125 \mathrm{~V}$ for 80 min. Samples containing lower concentrations of protein were first concentrated by Strata Clean resin (Stratagene) prior to loading on the gel. Gels were stained with Simply Blue TM Safe Stain (Invitrogen) according to the manufacturer's protocol.

\section{Western Blotting for 6xHisTagged Proteins}

For western blotting a Xcell II Blot Module (Invitrogen) was used. The protein bands were transferred to nitrocellulose membrane in $1 \mathrm{X}$ Transfer buffer at 25 Volts for $1 \mathrm{~h}, 30 \mathrm{~min}$. Buffer containing $10 \mathrm{~mL}$ of $5 \%$ milk powder in phosphate buffered saline (PBS)-Tween 20 was used as blocking buffer. The blot was incubated with 10 $\mu \mathrm{L} \quad(1 / 1000 \quad$ diluted $)$ alkaline phosphatase conjugated-Mouse Anti-Hexa-His antibodies (Sigma) for $1 \mathrm{~h}$. and washed with $10-15 \mathrm{~mL}$ of PBS-Tween 20 three times for $5 \mathrm{~min}$ on a roller, and finally with PBS buffer. The blot was then developed using BCIP: 5-bromo-4-chloro-3indolyl phosphate; NBT: p-nitroblue tetrazolium chloride (BCIP/NBT) substrate (Sigma).

\section{Results and Discussion \\ Hvo Rada Over-Expressed as Soluble Proteins in E. Coli}

Recombinant 6x His-tagged RadA was over-expressed from pBPRAD1 in the Rosetta 2 (DE3) E. coli expression strain. SDS-PAGE analysis showed the optimum induction of RadA after $4 \mathrm{~h}$ of incubation at $25^{\circ} \mathrm{C}$ (Fig. 1a). The expression of halophilic proteins in a mesophilic host, like E. coli has been shown to associate with 
the protein insolubility, which was reversed to soluble form by the denaturation and subsequent refolding of protein [17]. In previous studies of Hvo PCNA and RPA3 demonstrated that overexpression of halophilic protein in $E$. coli could be successful and can yield a reasonable quantity of soluble proteins for the structural and functional analysis [18, 19]. The over-expression of Hvo RadA in E. coli gave a reasonable amount of soluble proteins. The soluble protein yield was confirmed through the presence of a prominent RadA band (at the estimated molecular weight of $\sim 38 \mathrm{kDa}$ ) in the soluble lysate by SDS-PAGE (Fig. 1b). His-tagged RadA presence was later confirmed by western blot using anti-His antibody (Fig. 1c).

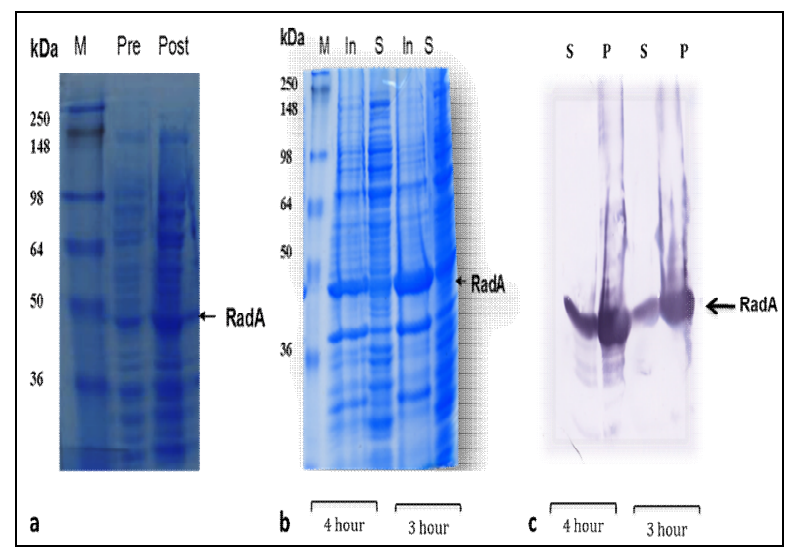

Figure 1a. Over-expression of RadA in E. coli. SDS-PAGE showing the total proteome of cells before induction (Pre) and after induction (Post) of over-expressed RadA proteins. Protein standard (kDa) are indicated in Lane M. b. A time course for the insoluble and soluble proteome analysis of $E$. coli cells. SDS PAGE showing RadA protein after the induction at 3 and 4 hrs. c. Western blot analysis showing insoluble protein (In) in the pellet and soluble protein $(S)$ in the supernatant over a time course of 3 and 4 hours. Molecular weight standards (kDa) are indicated in Lane M

\section{Estimation of Molecular Weight of RadA}

The initial purification was achieved by Talon metal affinity chromatography which separates proteins based on the affinity of His-tag with $\mathrm{Co}^{2+}$ metal-based resins. The eluted proteins were further purified using SEC column. To estimate the molecular weight of $\operatorname{RadA}$, SEC protein standards (Bio-Rad) were run on the column under similar buffering conditions (Fig. 2) and the protein peaks were plotted on a logarithmic scale by taking Molecular Weight (MW) (kDa) on $\mathrm{y}$-axis and elution volume $(\mathrm{mL})$ on $\mathrm{x}$-axis. A bestfit line was calculated to permit conversion of fraction numbers of unknown proteins to predict molecular weights (data not shown). RadA protein was observed to elute earlier than would be predicted for a monomer, between a volume of 110-170 mL. The shoulder peak between 140 to $170 \mathrm{~mL}$ corresponds to $\sim 450-150 \mathrm{kDa}$, suggesting multimeric state of $\operatorname{RadA}$ in solution, probably forming dimers of heptameric rings. A comparative superimposed chromatographic traces is presented in Fig. 2.

SEC traces in Fig. 2 show a high absorbance as compared to the proteins visualized by SDS-PAGE analysis, suggesting that nonprotein debris (DNA contamination) is contributing to the enhanced $\mathrm{UV}$ reading in addition to the suspected oligomeric forms of RadA [14]. Agarose gel analysis of fractions obtained in the shoulder peak (Fractions 3-6 at 130-160 mL) indicated that RadA co-purifies with the host DNA (gels not shown).

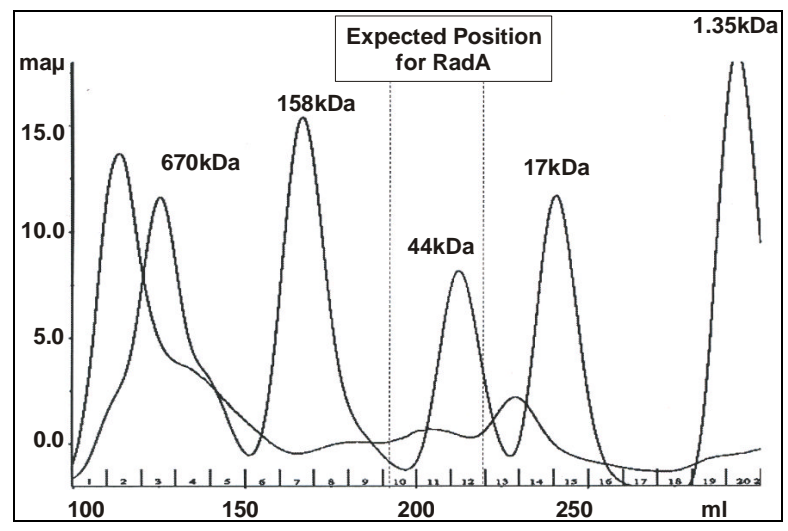

Figure 2. Calibration of S200 column with known molecular weight standards

A chromatogram showing molecular weight markers run in the same buffer on the equivalent column (S200) to estimate the molecular weight of $\operatorname{RadA}$. A trace of $\operatorname{RadA}$ is superimposed (Blue).

\section{RadA-DNA Interaction Strengthen with High Salt in the Mesophilic Host}

The solubility of halophilic proteins is usually maintained in the high salt medium and the removal of salt can inactivate the enzymatic activity [20, 21] or decrease the solubility of protein [17, 22]. To purify $\operatorname{RadA}$ from contaminating DNA, Polyethylenimine PEI assay 
was performed in $1 \mathrm{M} \mathrm{NaCl}$. (PEI) was used to precipitate DNA at $5 \%[\mathrm{w} / \mathrm{v}]$ final concentration in $50 \mathrm{mM}$ Tris- $\mathrm{HCl}$ buffer, $\mathrm{pH}$ 7.5. PEI, being a cationic polymer, strongly interacts with anionic molecules, like DNA. Soluble lysate containing RadA was mixed with PEI in a drop-wise manner with continuous stirring on ice until precipitated into a cloudy solution. The mixture was then centrifuged for $10 \mathrm{~min}$ at $4000 \mathrm{rpm}$. The presence of RadA and DNA was monitored by SDS-PAGE and agarose gel analysis, respectively, in both the PEI treated supernatant (S) and pellets (P) (Fig. 3). DNA contamination was observed in either case. However, most of the RadA was observed in the supernatant and a residual quantity was found in the pellets. PEI at increased concentration is reported to precipitate protein from the supernatant in lower ionic strength medium $(0.1-0.2 \mathrm{M} \mathrm{NaCl})$. DNA- binding proteins mostly bind nucleic acid at lower salt concentrations and are recovered from the pellet at higher salt concentration. At higher salt concentration $(1 \mathrm{M})$ or medium ionic strength (0.2-1 M), the desired protein is expected to be in the supernatant, whereas nucleic acid is expected to precipitate in the pellets [23]. PEI precipitation was performed in $1 \mathrm{M} \mathrm{NaCl}$ and $\mathrm{RadA}$ was expected in the soluble fraction and nucleic acid in the insoluble pellet, however, agarose and SDSPAGE analysis showed almost equivalent distribution of DNA and protein in both the supernatant and pellet fractions, suggesting the dynamics of halophilic protein-DNA interactions are different than those from the mesophilic counterparts. Because the majority of RadA is retained in the supernatant after PEI precipitation, further purification of RadA was continued with this fraction using Talon and SEC. Agarose gel analysis of S200-purified fractions showed RadA co-purified with DNA and PEI precipitation assay could not purify RadA from DNA. Various other methods were made to disrupt the strong association of RadA to DNA and co-purification of RadA-DNA in every instance suggested that the protein-DNA interaction in halophilic organisms are quite different than in the other thermophilic and mesophilic counterparts. It has not been investigated whether the association of RadA to contaminated DNA is random or specific to particular DNA sequences in E. coli. Different methods, like ChIP (chromatin Immunopreci- pitation) technique coupled with high throughput sequence analysis (ChIP-seq) can identify specific DNA sites in direct physical interaction with the protein [24]. It would have been interesting to explore the DNA binding site of RadA in the $E$. coli genome through techniques like ChIP-seq analysis but there were certain limitations to perform this like lack of RadA-specific antibodies. However, in another separate study we found coexpression and co-purification of RAdA with its paralog $\mathrm{RadB}$, prevents the deleterious contamination of RadA from host's DNA [14].

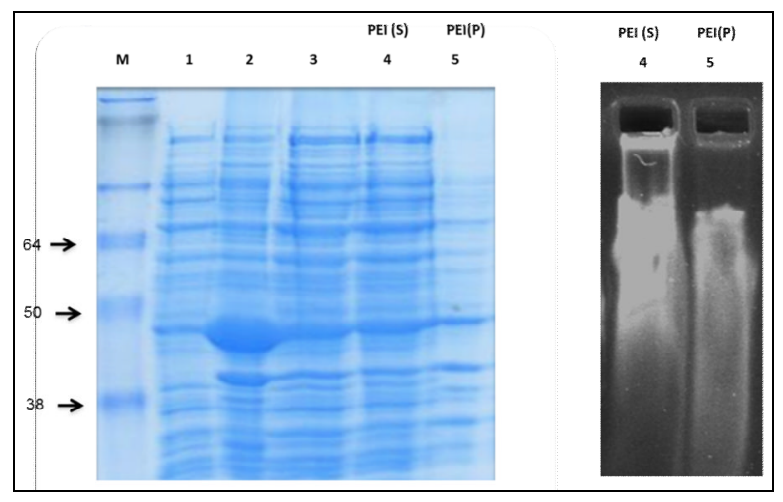

Figure 3. SDS-PAGE (Left) and DNA agarose gel (Right) analysis of soluble $E$. coli cell extract containing $\operatorname{RadA}$ precipitated with polyethylenimine. M=Marker (kDa), 1=RadA pre-induction, 2=post-4 $\mathrm{h}$ induction, 3=RadA incubated with PEI, 4=Supernatant of PEI-precipitated samples, $5=$ pellets after centrifugation of PEI precipitation

\section{Nuclease Treatment}

Digestion of polymeric DNA in the bacterial extract was performed to facilitate the purification of RadA. The cell extract was treated with commercially available nuclease with the trademark name, Benzonase ${ }^{\circledR}$ (Merck), to facilitate the recovery of RadA protein from the supernatant. The nuclease activity was optimized in buffers containing varying concentrations of $\mathrm{NaCl}$ (250 $\mathrm{mM}-1 \mathrm{M})$ at different length of time. The optimum activity was observed in buffers containing $20 \mathrm{mM}$ Tris $\mathrm{HCl} \mathrm{pH} 8.0,2 \mathrm{mM} \mathrm{MgCl}_{2}$, benzonase $(25 \mathrm{U} / \mu \mathrm{L}) 2 \mu \mathrm{L} / \mathrm{mL}$ and $500 \mathrm{mM} \mathrm{NaCl}$. (Fig. 4).

Agarose gel analysis of the corresponding fractions has suggested that DNA is masked by RadA and is limiting the digestion by benzonase enzyme. A partial unfolding of RadA using 
denaturants, like urea reduced the DNA contamination but could not help in the complete removal of bound DNA.

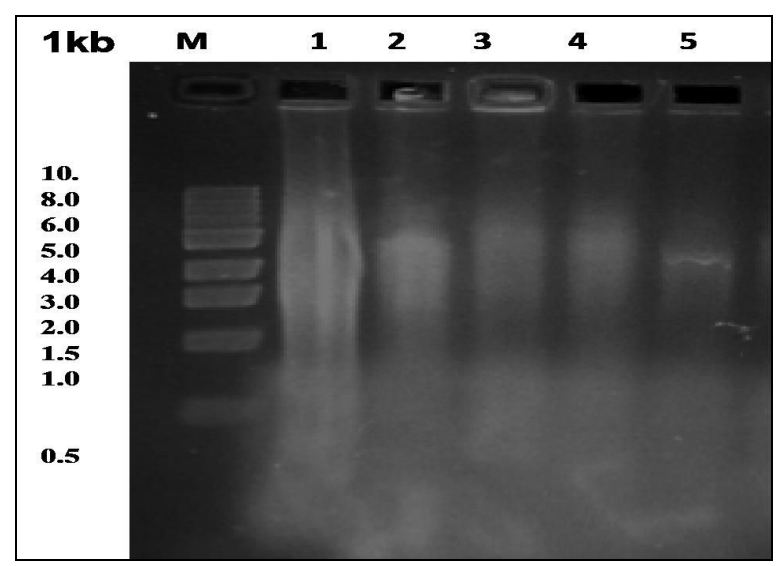

Figure 4. Time course for benzonase incubation with soluble lysate containing $\operatorname{RadA}$ in $500 \mathrm{mM} \mathrm{NaCl}$. M=1Kb ladder, 1= soluble lysate, $2=2 \mathrm{~h}$ incubation with benzonase $3=3 \mathrm{hr}$ incubation $4=4 \mathrm{~h}$ incubation $5=$ overnight incubation with fresh added benzonase $2 \mu \mathrm{L} / \mathrm{mL}(25 \mathrm{U} / \mu \mathrm{L})$

\section{Refolding of RadA}

Digestion of nucleic acid using benzonase in combination with $3 \mathrm{M}$ urea suggested that DNA is masked by $\operatorname{RadA}$ and is not accessible to the nuclease. Previous study has shown that halophilic proteins are successfully reactivated as soluble and functional protein after denaturation with urea [17]. In an attempt to remove the contaminating DNA, cell extract containing over-expressed RadA was treated with $6 \mathrm{M}$ urea in combination with the benzonase treatment. Halophilic proteins are reported to be quite stable under denaturing conditions [17]. The concentration of denaturant was gradually decreased as a gradient with the refolding buffer and elution of RadA was achieved in buffer containing $50 \mathrm{mM}$ HEPES, $1 \mathrm{M} \mathrm{NaCl}$ and $300 \mathrm{mM}$ imidazole. Fig. 5 and 6 shows that RadA purified up to $\sim 90 \%$ after on-column refolding process. Refolding of $\operatorname{RadA}$ in combination with nuclease treatment resulted in the purification of RadA from DNA contamination. The elution profile of RadA on SEC column suggested that $\operatorname{Rad} A$ retains the native original state as it had been observed in the-chromatograms (Fig. 6). However, in the absence of any previous functional characterization of this protein, it is difficult to speculate about the correct refolding of $\operatorname{RadA}$ and its functional form. In preliminary experiments,
RadA did not show any DNA-binding or ATPase activity. Since the expression system in $H$. volcanii was available at this stage of the study, further biochemical characterization was performed with RadA expressed in its native host $H$. volcanii in order to clear any ambiguity regarding the correct folding of RadA.

However, the over-expressed and purified RadA in the native host (i.e. $H$. volcanii) did not show DNA-dependent ATPase activity in several different attempts. This indicates that the reaction kinetics are quite particular for each $\operatorname{RadA}$ proteins in the strand exchange process [12, 13] and Hvo RadA may require some additional factors or optimal reaction conditions for the in vitro analysis in the band shift analysis and ATPase assay. In the future direction, the analysis of the purified renatured $\operatorname{RadA}$ by the methods, like Circular Dichroism (CD) spectroscopy and small angle Xscattering (SAXS) can be used to determine the correct and active folding state of protein.

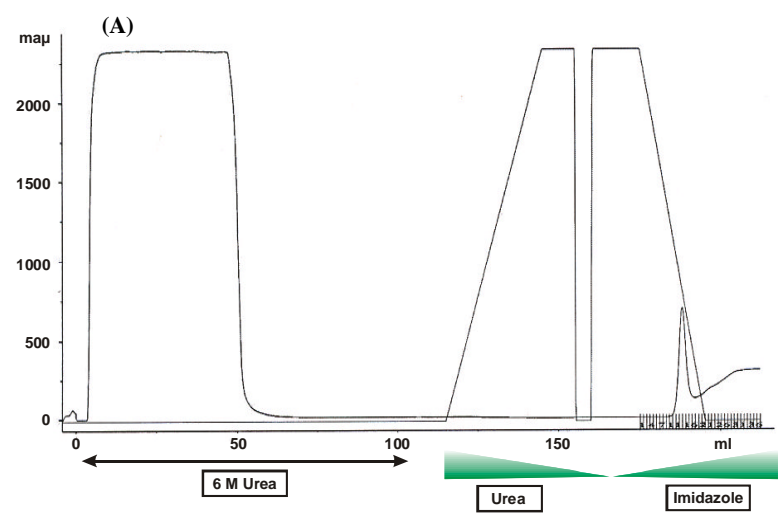

(B)

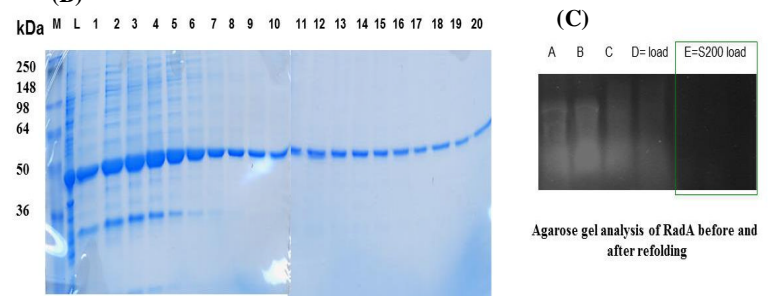

Figure 5. Refolding of RadA after denaturation in $6 \mathrm{M}$ urea.

(A) SEC chromatogram showing refolding of RadA using $5 \mathrm{~mL}$ Ni-based HisTrap column. (B) SDS-PAGE analysis of HisTrap fractions collected from $240-260 \mathrm{~mL}$ volume, corresponding to the collected UV absorbance peak. (C) DNA agarose gel electrophoresis of $\operatorname{RadA}$ before and after refolding. $A=$ Incubation of soluble lysate with benzonase for $2 \mathrm{~h}, \mathrm{~B}=$ Incubation with $6 \mathrm{M}$ urea, $\mathrm{C}=$ Incubation with fresh added benzonase, $D=$ On-column refolding using HisTrap, $E=$ S200 load (pooled fraction of HisTrap purified RadA) 


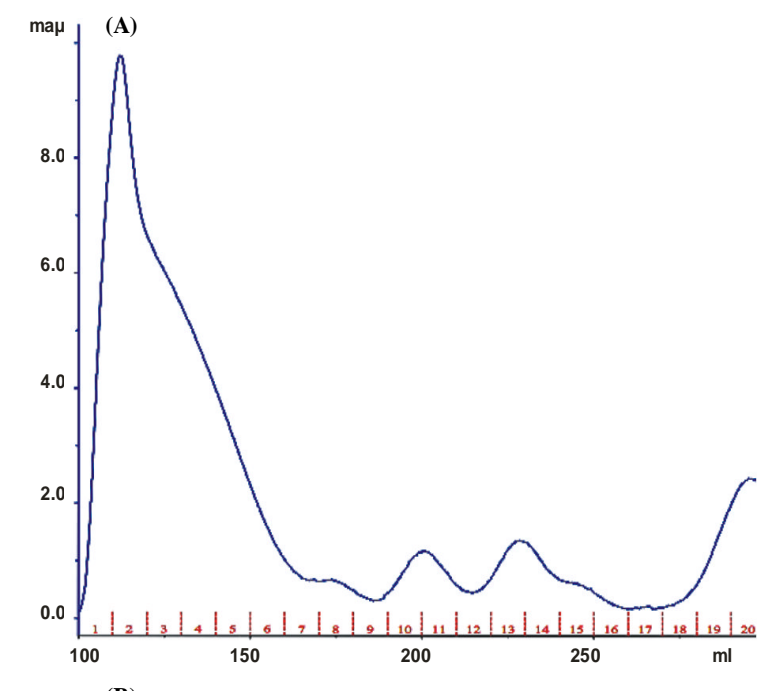

(B)
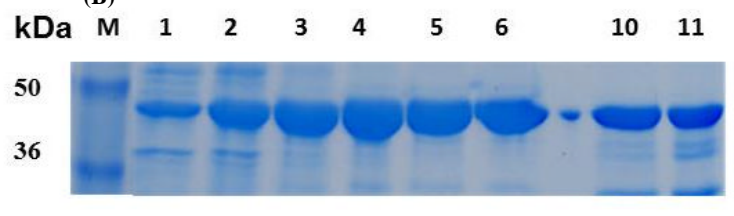

SDS-PAGE of RadA purified by SEC

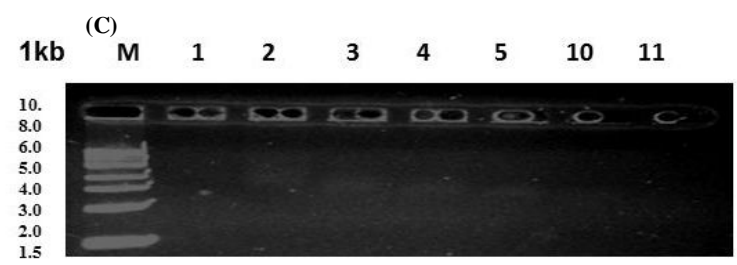

Agarose gel analysis of RadA fractions purified by SEC

Figure 6. SEC of RadA after refolding.

(A) A chromatogram showing the elution profile of RadA using a 26/60 Superdex 200 SEC column (B) \& (C) SDS-PAGE and agarose gel analysis of the obtained fractions (1-6 and 10-11) corresponding to the UV absorbance peak obtained at 110-160 $\mathrm{mL}$ and 200-210 $\mathrm{mL}$, respectively.

\section{Conclusion}

The present study demonstrates the successful expression of halophilic recombination protein, RadA, in E. coli. However, in the present study denaturation of RadA was performed in an attempt to purify RadA from DNA. Purification and characterization of halophilic proteins is often hampered due to the restriction of purification methods as they require a high salt concentration to maintain the proteins in a folded state. The standard methods of purification of DNA binding proteins usually employ low ionic strength buffers that may adversely affect the enzymatic activity and hamper the purification of halophilic proteins. For example, proteins with DNA-binding affinity are usually purified by ion-exchange chromatographic method (e.g. DEAE-cellulose) or heparin affinity chromatography, which may not be suitable for the halophilic proteins due to the application of protein in low salt. For the purification of Hvo RadA, protocols were adapted to high ionic strength of medium $(1 \mathrm{M} \mathrm{NaCl})$ to maintain the solubility of proteins and purification is achieved by denaturation with the subsequent refolding of protein. Purified RadA protein at this stage could not be assessed by biochemical (functional) activities, such as, band shift analysis (EMSA) and ATPase assay and can be targeted in future studies.

\section{Acknowledgments}

We pay special regards to Dr. Karen A. Bunting and Dr. Jody A. Winter for their guidance and help to execute this research work.

\section{Funding}

The project was funded by HEC Pakistan and University of Sindh, Jamshoro, and executed in the School of Biology, Queens Medical Centre, University of Nottingham, Nottingham, NG7 2UH, UK.

\section{Ethical compliance statement}

Authors declare that the current research work does not involve any human participant or animal model. It is also declared herewith that there is no conflict of interests in the current manuscript.

\section{References}

1. S. C. Kowalczykowski, and A. K. Eggleston, Annu. Rev. Biochem., 63 (1994) 4. https://doi.org/ 10.1146/annurev.bi.63.070194.005015.

2. A. K. Eggleston, and S. C. Kowalczykowski, Biochimie, 73 (1991) 2-3. https://doi.org/10.1016/j.biochi.2019.09.005.

3. J. W. Szostak, T. L. Orr-Weaver, R. J. Rothstein, F.W. Stahl, Cell, 33 (1983) 1. 
https://doi.org/10.1016/0092-

8674(83)90331-8

4. R. M. Story, I. T. Weber and T. A. Steitz, Nature, 355 (1992) 6358.

https://doi.org/ 10.1038/355318a0.

5. A. Shinohara, H. Ogawa and T. Ogawa, Cell., 69 (1992) 3.

https://doi.org/10.1016/0092-

$\underline{\text { 8674(92) } 90447-\mathrm{k}}$

6. E. M. Seitz, J. P. Brockman, J. P. Sandler, S.

J. Clark, S. C. Kowalczykowski, Genes Dev., 12 (1998) 9.

https://doi.org/10.1101/gad.12.9.1248

7. P. R. Bianco, R. B. Tracy and S. C. Kowalczykowski, Front Biosci., 3 (1998) 2. https://doi.org/10.2741/a304

8. M. F. Mullakhanbhai and H. Larsen, Arch. Microbiol., 104 (1975) 3.

https://doi.org/10.1007/BF00447326

9. D. Sheng, L. M. Feng, J. J. Dong, N. J. Feng, S. Y. Longet, Sci. China. C. Life. Sci., 51 (2008) 1.

https://doi.org/10.1007/s11427-008-0008-x.

10. K. Komori, T. Miyata, J. DiRuggiero, R. H. Shanks, I. Hayashi, I. K. O. Cann, K. Mayanagi, H. Shinagawa, Y. Ishino, J. Biol. Chem., 275 (2000) 43.

https://doi.org/10.1074/jbc.M004557200.

11. D. S. Shin, L. Pellegrini, D. S. Daniels, B. Yelent, L. Craig, D. Bates, D. S. Yu, M. K. Shivji, C. Hitomi, A. S. Arvai, N. Volkmann, H. Tsuruta, T. S. Blundell, A. R. Venkitaraman, J. A. Tainer, Embo. J., 22 (2003) 17.

https://doi.org/10.1093/emboj/cdg429.

12. M. J. McIlwraith, D. R. Hall, A. Z. Stasiak, A. Stasiak, D. B. Wigley, S. C. West, Nucleic Acids Res., 29 (2001) 22.

https://doi.org/10.1093/nar/29.22.4509

13. X. Qian, Y. He, X. Ma, M. N. Fodje, P. Grochulski, Y. Luo, J. Biol. Chem., 281 (2006) 51

https://doi.org/ M607785200

[pii]10.1074/jbc.M607785200.

14. B. B. Patoli, J. A. Winter, A. A. Patoli, R. M. Delahay and K. A. Bunting, Microbiol., 163 (2017) 12. https://doi.org/10.1099/mic.0.000562.
15. M. Takahashi, E. Takahashi, L. I. Joudeh, M. M. Marini, G. Das, M. M. Elshenawy, A. Akal, K. Sakashita, I. Alam, M. Tehseen, M. A. Sobhy, U. Stingl, J. S. Merzaban, E. D. Fabrizio and S. M. Hamdan, FASEB J., 32 (2018) 6. https://doi.org/10.1096/fj.201700862RR.

16. S. Bergqvist, M. A. Williams, R. O'Brien, and J. E. Ladbury, Biochem. Soc. Trans., 31 (2003) 3. https://doi.org/10.1042/.

17. O. Blecher, S. Goldman and M. Mevarech, Eur. J. Biochem., 216 (1993) 1. https://doi.org/ 10.1111/j.14321033.1993.tb18133.x

18. J. A. Winter, P. Christofi, S. Morroll and K. A. Bunting, BMC Struct. Biol., 9 (2009) 1. https://doi.org/1472-6807-9-55 [pii]10.1186/1472-6807-9-55.

19. J. A. Winter, B. Patoli and K. A. Bunting, Archaea., 1 (2012) 2. https://doi.org/ 10.1155/2012/719092.

20. F. Cendrin, J. Chroboczek, G. Zaccai, H. Eisenberg and M. Mevarech, Biochem., 32 (1993) 16. https://doi.org/10.1021/bi00067a020

21. L. Ai, Y. Huang and C. Wang, J. Basic Microbiol., 58 (2018) 8. https://doi.org/10.1002/jobm.201800116.

22. H. Connaris, J. B. Chaudhuri, M. J. Danson, D. W. Hough, Biotechnol. Bioeng., 64 (1999) 1. https://www.ncbi.nlm.nih.gov/pubmed/1039 $\underline{7837}$

23. R. R. Burgess, Methods Enzymol., 208 (1991) 10. https://doi.org/10.1016/00766879(91)08003-Z

24. D. Schmidt, M. D. Wilson, C. Spyrou, G. D. Brown, J. Hadfield and D. T. Odom, Methods, 48 (2009) 3. https://doi.org/10.1016/j.ymeth.2009.03.001. 